\title{
ANODE MATERIALS BASED ON GRAPHENE FOR LITHIUM-ION BATTERIES
}

Denis Yu. Kornilov

«AkKo Lab» LLC, http://akkolab.ru/en/

129110 Moscow, Russian Federation

akkolab@gmail.com

Sergey P. Gubin

Kurnakov Institute of general and inorganic chemistry, Russian Academy of Sciences, http://www.igic.ras.ru/en/ 119991 Moscow, Russian Federation

gubin@igic.ras.ru

Abstract. Despite modern technological advances, the creation of powerful, energy-intensive and environmentally friendly energy storage devices is an actual problem. Lithium-ion batteries (LIBs), which have a high density of stored energy and low self-discharge, are the priority in the list of advanced energy storage devices. Performance of LIB depends on the composition and structure of the materials used to create the cathodes and anodes. Recently, among the new materials focusing on graphene combines a number of unique properties of the defining prospects use as electrode materials. This review summarizes the modern main achievements of the period from 2013 by 2015 in the area of graphene application and composite materials on its basis, as materials for the LIB electrodes.

Keywords: lithium-ion battery, graphene, graphene oxide

UDC 621.3.035.221.15

Bibliography -82 references

Received 18.06.2016

RENSIT, 2016, 8(1):39-48

DOI: $10.17725 /$ rensit.2016.08.039

Contents

1. INTRODUCTION (39)

2. Graphene AS AN ANODE MATERIAL FOR LIB (40)

3. Anode materials based on spheres of GRAPHENE (40)

4. Anode materials based ON TIN AND GRAPHENE (40)

5. ANOdE MATERIALS BASEd ON SILICON AND GRAPHENE (41)

6. Anode materials based on metal oxides AND GRAPHENE (42)

7. Graphene as a modificator of Lithium ANODE (43)

8. Conclusion (43)

REFERENCES (44)

\section{INTRODUCTION}

Nanomaterials of various composition and morphology are widely used in research works on creation of innovative electrodes for LIB [1]. Despite of large number of commercially available LIBs types [2-8] they do not meet the requirements of various consumers, both military and civil. There is a need of increase of capacity, rate of the charge/discharge, cycle-life, decrease in cost value of $\mathrm{LIB}$, reduction of toxicity and fire danger. This initiates a search of new materials [9, 10] and batteries manufacturing technology that would allow producing light, compact and more capacitive devices of energy storage.

One way of solving these problems is use of a graphene as a part of the electrode material [11, 12]. Graphene has a high conductivity, a high surface area $\left(2640 \mathrm{~m}^{2} \cdot \mathrm{g}^{-1}\right)$ and capabilities of withstanding the enormous current density (more than $10^{7} \mathrm{~A} \cdot \mathrm{cm}^{-2}$ ) [13]. Maximum of charge carrier mobility in singlelayergrapheneat room temperature is 200.000 $\mathrm{cm}^{2} \cdot \mathrm{V}^{-1} \cdot \mathrm{s}^{-1}[14]$. Graphene is the most durable material (Young's modulus 1TPa) and it can 
be subjected to considerable deformation without breaking the crystal lattice [15]. The next advantage in favor of the use of graphene in the LIB is the use of its derivatives, such as graphene oxide. At this time the graphene and graphene oxide are made by a row of companies [16, 17] and these materials are quite available.

\section{GRAPHENE AS AN ANODE MATERIAL FOR LIB}

The high surface area, high electrical conductivity, strength and plasticity of graphene point out to applicationway of graphene as ananode material for a LIB. Especially that graphite uses in LIBs produced by modern industry successfully, and intercalated capacity (that is, the quantity of electricity, which can be transferred to fully charged electrode, per unit mass or volume) of graphite relative to the lithium electrode is $372 \mathrm{~mA} \cdot \mathrm{h} \cdot \mathrm{g}^{-1}$ [2]. In most publications, Hammers' method uses as a main synthesis method of graphene for anodes LIB [12], which is compared with the CVD synthesis method is technically more simple. Research results indicate values of intercalation capacity of graphene from 165 to $1400 \mathrm{~mA} \cdot \mathrm{h} \cdot \mathrm{g}^{-1}$ of [16-41] that in the case of high values of capacitance are not consistent with the theoretical model of intercalation (inserts between layers)/deintercalation of lithium into the graphite structure [1]. However, some authors do attempts a theoretical explanation of the increased intercalation capacity of graphene compared to graphite [42-45] by the presence of defects in the structure of graphene flakes.

\section{ANODE MATERIALS BASED ON SPHERES OF GRAPHENE}

Some scientists give various forms to cathode materials for increasing of them capacity, for example, it is demonstrate the possibility of spheres creation from graphene flakes [46, 47]. The method was based on few steps: it is needed into aqueous dispersion of graphene oxide poured slowly an olive oil which warmed

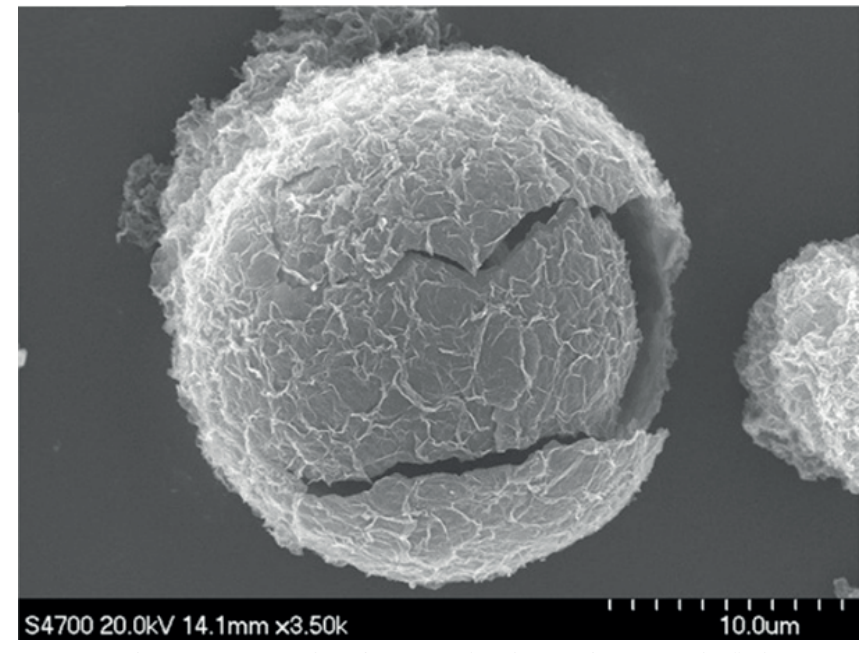

Fig. 1. SEM image of sphere made of graphene oxide flakes [46] up to $90^{\circ} \mathrm{C}$; after that the mixture was heated to $95^{\circ} \mathrm{C}$ for gradually evaporating water. Next, spheres thus obtained (Fig. 1) were separated from the dispersion by centrifugation, followed by thermal reduction to form graphene.

Electrochemical tests of the resulting microspheres as the anode material showed excellent results, the maximum discharge capacity (MDC) in the first cycle charge/discharge was $903 \mathrm{~mA} \cdot \mathrm{h}^{-\mathrm{g}^{-1}}$ at a discharge current of $\mathrm{C} / 18$, upon further cycling capacity of the material decreased to $652 \mathrm{~mA} \cdot \mathrm{h} \cdot \mathrm{g}^{-1}$. Unfortunately, the paper provides no data concerning the surface area of the resulting microspheres.

Similar spheres $(\mathrm{d}=30-40 \mathrm{~nm}$, BET area of $733 \mathrm{~m}^{2} \cdot \mathrm{g}^{-1}$ ) can be prepared by mixing aqueous solutions of melamine and graphene oxide, followed by melamine lyophilization and thermal reduction to graphene at $800^{\circ} \mathrm{C}$ in argon; discharge capacity of $1454 \mathrm{~mA} \cdot \mathrm{h} \cdot \mathrm{g}^{-1}$ at a current $0.27 \mathrm{C}$ and 200 cycles of charge/discharge.

\section{ANODE MATERIALS BASED ON TIN AND GRAPHENE}

Graphene as the anode material is modified with various additives $[48,49]$. There are a number of metals wich have reversible intercalation capacity relative to lithium. For example, for usable tin a value is $991 \mathrm{~mA} \cdot \mathrm{h}^{-\mathrm{g}^{-1}}[3]$ andit makes the metal very promising anode material. However, lithium increases a volume of the crystal lattice of tin more than 3 times during doping process, that 
inevitably leads to the gradual destruction of the electrode. In that context researchers do large amount of scientific work around the world to find ways to stabilize the anode based on tin during cycling.

Formation containment made of graphene is one of ways to increasing of electrochemical strength and capacity of anode materials based on tin. Qin et al. [50] have obtained tin/ graphene composite by mixing graphene oxide and tin ethylhexanoate in ethanol, followed by autoclaving at $160^{\circ} \mathrm{C}$ for 10 hours. This resulted in reduction of the graphene oxide flakes to form of tin nanoparticles on their surface with size of 3 to $5 \mathrm{~nm}, \mathrm{MDC}=811 \mathrm{~mA} \cdot \mathrm{h} \cdot \mathrm{g}^{-1}$ (500 charge/discharge cycles). It is shown that increasing of tin particle size from 100 to 300 $\mathrm{nm}$ results in decreasing of capacitive indicators $\left(\mathrm{MDC}=440 \mathrm{~mA} \cdot \mathrm{h} \cdot \mathrm{g}^{-1}, 55\right.$ charge $/$ discharge cycles) [51-53].

Variation of tin particles form does not lead to an improvement in capacity characteristics. Liu et al. [54] have obtained nanoflakes of tin oxide with thickness up to $10 \mathrm{~nm}$ and a lateral size up to $500 \mathrm{~nm}\left(\mathrm{MDC}=450 \mathrm{~mA} \cdot \mathrm{h}^{-1} \mathrm{~g}^{-1}, 100\right.$ charge/ discharge cycles). Guo et al. [55] have obtained nanoparticles of tin oxide on the surface of the reduced graphene oxide flakes with size up to 40 $\mathrm{nm}$ and a structure of «nanoflower» (MDC = $691 \mathrm{~mA} \cdot \mathrm{h} \cdot \mathrm{g}^{-1}, 50$ charge/discharge cycles).

Sometimes scientists use tin oxide on the anode surface as a source of tin. Dhanabalan et al [56] have obtained composite of tin oxide/ graphene by method of solution synthesis, MDC was from 534 to $737 \mathrm{~mA} \cdot \mathrm{h} \cdot \mathrm{g}^{-1}$ for 70 cycles. Also modification of graphene can be used. For example, Lin et al. [57] have used nanoribbons of graphene (made of carbon nanotubes [58]), with tin oxide nanoparticles.As a result a composite anode material was obtained with MDC $825 \mathrm{~mA} \cdot \mathrm{h} \cdot \mathrm{g}^{-1}$ during 50 charge/discharge cycles. Thus, it is shown that modification of graphene-based anode with metals in various forms can significantly improve the capacitive characteristics.

\section{ANODE MATERIALS BASED ON SILICON AND GRAPHENE}

The theoretical intercalation capacity of silicon relative to lithium is sufficiently high (4200 $\mathrm{mA} \cdot \mathrm{h} \cdot \mathrm{g}^{-1}$ [1]), that attracts the attention of researchers to creation of anodes based on it. However, as in the case of tin, volume of the material increases by 4 times at introduction of lithium ions into crystal lattice of silicon, which leads to the destruction of the electrode within 10-20 charge/discharge cycles.In order to eliminate this negative effect, researches try to create a composite material silicon/ graphene.

Synthesis of composite materials based on silicon and graphene is carried out by solution methods in two ways: by volatile metal-organic compounds (MOC) chemical vapor deposition (CVD) or by mixing silicon nanoparticles with flakes of graphene. Zhou et al. [59] produced an ultrasonic dispersion of solution containing silicon nanoparticles with an average size up to $100 \mathrm{~nm}$ and flakes of graphene oxide, then the resulting dispersion was filtered out and the product of synthesis was subjected to high-temperature treatment. The high value of $\mathrm{MDC}=1500 \mathrm{~mA} \cdot \mathrm{h} \cdot \mathrm{g}^{-1}$ was achieved at a current of 1C, during over 200 charge/discharge cycles. But more important to note, authors [59] obtained high capacitance values per unit area (6 $\mathrm{mA} \cdot \mathrm{h} \cdot \mathrm{cm}^{-2}$ ), for comparison we recall that the capacity of an anode based on graphite in modern LIBs does not exceed $4 \mathrm{~mA} \cdot \mathrm{h} \cdot \mathrm{cm}^{-2}$. Thus, the authors of this study have demonstrated a real opportunity to increase the power consumption of the LIBin a case of using silicon/graphene composites. The achieved values of capacitance is quite reproducible; so Gao et al. [60] got the value of MDC equal $1250 \mathrm{~mA} \cdot \mathrm{h} \cdot \mathrm{g}^{-1}$.

The change of morphology of silicon nanoparticles, like a transition to whiskers, allowed increasing the capacity up to 1600 $\mathrm{mA} \cdot \mathrm{h} \cdot \mathrm{g}^{-1}$ for 100 charge/discharge cycles [61].

Changing of morphology of currentcollector material can also affect the capacity 
characteristics of LIB. Thus, Chang et al. [62] deposited dispersions of graphene oxide and silicon nanoparticles $(100 \mathrm{~nm})$ in ethanol layerby-layer on the surface of porous nickel foam by aerograph. Value of MDC was achieved equal $780 \mathrm{~mA} \cdot \mathrm{h} \cdot \mathrm{g}^{-1}$ at a current of $3 \mathrm{C}$ during over 300 charge/discharge cycles.

In most studies tetrachlorosilane is used as a source of silicon for the CVD method $[63,64]$, which decompose at temperatures above $700^{\circ} \mathrm{C}$ with formation of silicon. Thus, dispersion of graphene oxide in water with a concentration of $0.7 \mathrm{mg} / \mathrm{ml}$ was frozen in liquid nitrogen in research work [65]. The resulting sample of graphene oxide was reduced by hydrogen at $1000^{\circ} \mathrm{C}$. Next, according to research work [63], tetrachlorosilane was introduced by injection, as result of which on the surface of the reduced graphene oxide flakes were formed silicon nanoparticles with a size of 5 to $10 \mathrm{~nm}$. Authors have achieved the MDC equal 1103 $\mathrm{mA} \cdot \mathrm{h} \cdot \mathrm{g}^{-1}$ for 1000 cycles at $14 \mathrm{C}$ charge current, discharge current was $2 \mathrm{C}$, also they have reproduced achieved capacity characteristics of the anode in the model assembly of LIB, where $\mathrm{LiCoO}_{2}$ was used as a cathode. In this research the degree of volume changes during the intercalation as for silicon nanoparticles so too for the whole of anode material was investigated in detail. It is established increase of the volume of silicon nanoparticles by intercalation of lithium into their crystal lattices, and comeback to the original volume at deintercalation, i.e. nanoparticles' vary reversibly, but the electrode as a whole remains unchanged (Fig. 2).
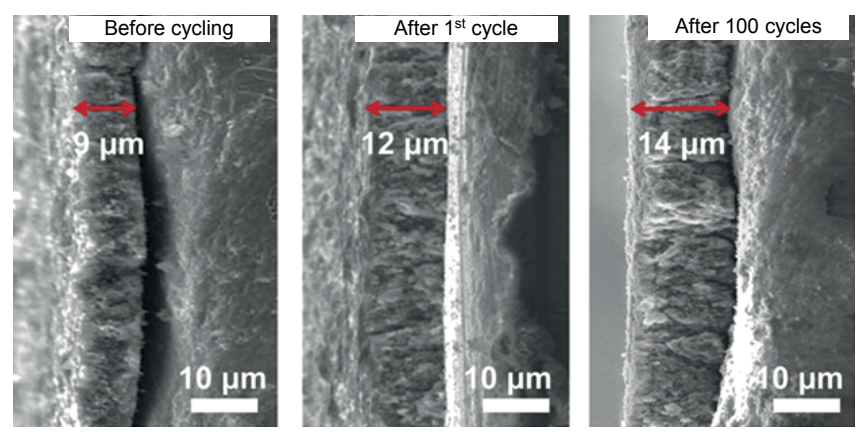

Fig. 2. SEM image layer of anode material during cycling [63].
Higher values MDC $821 \mathrm{~mA} \cdot \mathrm{h} \cdot \mathrm{g}^{-1}$, for 700 charge/discharge cycles at a current of $1 \mathrm{~A} \cdot \mathrm{g}^{-1}$ were obtained in $[64,65]$, where material having a tubular morphology based on layers of silicon and graphene was created.

Thus, it is shown that the combination of high intercalation capacity of silicon, high mechanical strength and electrical conductivity of graphene allows to create promising materials for anode of LIB.

\section{ANODE MATERIALS BASED ON METAL OXIDES AND GRAPHENE}

It is known that metal oxides $\left(\mathrm{Fe}_{3} \mathrm{O}_{4}, \mathrm{Mn}_{3} \mathrm{O}_{4}\right.$, $\mathrm{CuO}, \mathrm{MoO}_{2}, \mathrm{TiO}_{2}$ ) have a certain intercalation capacity relative to lithium, but they are not allow to use them in the pure form as an anode material. It is assumed, that use composites metal oxide/graphene may increase the capacity and cyclic life of LIBs. Below, we analyze the results of studies of the respective composite materials as anodes.

Thus, MDC varied just in range of 130 to $250 \mathrm{~mA} \cdot \mathrm{h} \cdot \mathrm{g}^{-1}$ depending on rate of the charge and discharge for composites of titanium oxide/ graphene [66-70]. A similar composite gave out MDC levels at 247, 238, 225, 210, 187 and 175 $\mathrm{mA} \cdot \mathrm{h} \cdot \mathrm{g}^{-1}$ at discharge currents of $0.1,0.2,0.5,1$, 2.5, and 5C, which was described in [69].

Modification graphene oxide by microwave processing in a composite of titanium oxide/ graphene [71] did not lead to a substantial increase of MDC and it was $150 \mathrm{~mA} \cdot \mathrm{h} \cdot \mathrm{g}^{-1}$.

Modification of titanium oxide by tin oxide additives leads to a significant increase in capacity characteristics at a discharge current of $0.1,0.2$, 0.5 and $1 C$, MDCs was 1473, 1043, 814 and 570 $\mathrm{mA} \cdot \mathrm{h} \cdot \mathrm{g}^{-1}$ [72].

Lithium titanate (LTO) relate to the compounds of titanium having the intercalation capacitance, and it is used in industrial output lithium-ion batteries.The maximum theoretically possible intercalation capacity of this material is $175 \mathrm{~mA} \cdot \mathrm{h} \cdot \mathrm{g}^{-1}$ [73], which is considerably inferior to graphite used in the 
manufacture of modern LIBs. However, lithium titanate is able to withstand high load currents up to $10 \mathrm{C}$ without loss of capacity. Naturally it was a desire of researchers to use composite of LTO/graphene as an anode material. $\mathrm{Li}_{4} \mathrm{Ti}_{5} \mathrm{O}_{12}$ was prepared by mechanochemical synthesis of $\mathrm{TiO}_{2}$ and $\mathrm{Li}_{2} \mathrm{CO}_{3}$. The resulting $\mathrm{Li}_{4} \mathrm{Ti}_{5} \mathrm{O}_{12}$ was introduced into dispersion of graphene oxide in water followed by addition of hydrazine hydrate for reducing of graphene oxide. Unfortunately, the hopes of obtaining an anode material with high values of capacity were not justified, so the discharge capacities of LTO/graphene obtained in [74] were 167, 156, 145 and 104 $\mathrm{mA} \cdot \mathrm{h} \cdot \mathrm{g}^{-1}$ at a discharge current of $1,5,10$ and $20 \mathrm{C}$.

Manganese oxides are widely used in standart batteries. The composite of graphene/ $\mathrm{MnO}$ described in [75], showed high values of MDC $700 \mathrm{~mA} \cdot \mathrm{h} \cdot \mathrm{g}^{-1}$ at $3 \mathrm{C}$ discharge current. Changes in the morphology of the manganese oxide samples are the creation of nanofibers, which are not significantly improve LIBs characteristics, but they store them on a high enough level (MDC $705 \mathrm{~mA} \cdot \mathrm{h} \cdot \mathrm{g}^{-1}, 100$ charge/discharge cycles) [76]. It is interesting to note that the reduced metallic $\mathrm{Mn}$ in alloy with $\mathrm{Si}$ demonstrates a significant capacitive characteristics $605 \mathrm{~mA} \cdot \mathrm{h} \cdot \mathrm{g}^{-1}$ during 50 charge/discharge cycles [77]. These results indicate that initial valence state of the metal in anode material $\left(\mathrm{Mn}^{+2}, \mathrm{Mn}^{+4}, \mathrm{Mn}^{0}\right)$ has no influence on the capacitive characteristics. Apparently, the same form of the metal realized for three cases of valence in the first cycles of the LIB charge/discharge.

The above methods of formation of metal oxide/graphene composites as a material for anodes LIBs usually used for anode materials with other oxides also. So in some research [78, 79] composite of molybdenum oxide/graphene gave out MDCs 1040, 930, 727 and $610 \mathrm{~mA} \cdot \mathrm{h} \cdot \mathrm{g}^{-1}$ at discharge currents of $0.1,0.2,0.5$ and $1 \mathrm{C}$. Essentially similar results were obtained in [79] where the MDCs was 1100, 900, 680 and 610 $\mathrm{mA} \cdot \mathrm{h} \cdot \mathrm{g}^{-1}$ at discharge currents of $0.1,0.5,5$ and
10C. At the same time, an interesting method was proposed in [80]. The authors [80] have applied the method «spraypyrolysis», which consists in spraying the solution containing flakes of graphene oxide and the salt of Mo (VI) in a chamber at $900^{\circ} \mathrm{C}$. The discharge capacity of the result material was $975 \mathrm{~mA} \cdot \mathrm{h} \cdot \mathrm{g}^{-1}$ for 100 cycles.

\section{GRAPHENE AS A MODIFICATOR OF LITHIUM ANODE}

Recall that one of the first materials used as an anode of LIB was the metallic lithium pure and simple. One of disadvantages of the material is dendrites which formed on the LIB anode surface under a sufficiently long cycling and germinated through a separator that led to short circuit with a cathode. Thus, coating film of reduced graphene oxide for lithium makes it possible to eliminate the germination dendrites [81].

Kim et al. [82] have used another approach and they have transferred CVD graphene on a surface of lithium foil. The capacitance of developed electrode was $4 \mathrm{~mA} \cdot \mathrm{h} \cdot \mathrm{cm}^{-2}$ in terms of unit surface. This means that the graphene layer resists the formation and sprouting of dendrites. These first experiments indicate the possibility of the use of graphene as a protective coating of lithium anode, and therefore the possibility of increase of capacity of LIB with the use of new high-capacity and safe anode.

\section{CONCLUSION}

From this brief review of the first publications follows that graphene having a set of unique properties has to find widespread use in modern LIBs, not only as an anode material but also as a conductive additive, the reinforcing element and the protective coating. The large range of used synthesis methods allows creating a graphene-based functional materials with various morphology, physical and chemical characteristics, this is a huge advantage of it over other tested materials. 


\section{REFERENCES}

1. Yaroslavtsev AB, Kulova TL, Skundin AM. Electrode nanomaterials for lithium-ion rechargeable battery. Russ. Chem. Rev., 2015, 84:826-852.

2. Wu Y. Lithium-ion Batteries, Fundamentals and Applications. NY, Taylor \& Francis Group, 2015, p. 568.

3. Goodenough J, Park K. The Li-Ion Rechargeable Battery: A Perspective. J. Am. Chem. Soc., 2013, 135:1167-1176.

4. Warner JT. The Handbook of Lithium-Ion Battery Pack Design. Chemistry, Components, Types and Terminology. Elsevier Science, 2015, p. 262.

5. Gulbinska MK (Ed.). Lithium-ion Battery Materials and Engineering. London, Springer, 2014, p. 205.

6. Chudinov EA, Tkachuk SA, Shishko VS. Tekhnologicheskie osnovy proizvodstva litiy-ionnogo akkumulyatora [Technological basis of lithium-ion battery production]. Elektrokhimicheskaya energetika, 2015, 15(2):8492 (in Russ.).

7. Jiang J, Zhang C. Fundamentals and applications of lithium-ion batteries in electric drive vehicles. Singapore, Wiley, 2015, p. 280.

8. Link AN, O'Connor AC, Scott TJ. Battery Technology for Electric Vebicles. NY, Routledge, 2015, p. 129

9. Srivastava M, Singh J, Kuila T, Layek R, Kim $\mathrm{N}$, Lee J. Recent advances in graphene and its metal-oxide hybrid nanostructured for lithium-ion batteries. Nanoscale, 2015, 7:4820. DOI: $10.1039 / C 4 N R 07068 B$.

10. Luo B., Zhi L. Design and construction of three dimensional graphene-based composites for lithium-ion battery applications. Energy Environ. Sci., 2015, 8:456477. DOI: 10.1039/C4EE02578D.

11. Gubin SP, Tkachev SV. Grafen i rodstvennye nanoformy ugleroda [Graphene and carbon related nanoforms]. Moscow, URSS LENAND, 2015, Issue 4, pp. 112.

12. Ferrari A. et al. Science and technology roadmap for graphene, related two-dimensional crystals, and hybrid systems. Nanoscale, 2015, 7:4598-4810. DOI: 10.1039/ C4NR01600A.

13. Baringhaus J, Ruan M, Edler F, Tejeda A, Sicot M, Taleb-Ibrahimi A, Li A-P, Jiang Z, Conrad EH, Berger C. Tegenkamp C, de Heer WA. Exceptional ballistic transport in epitaxial graphene nanoribbons. Nature, 2014, 506:349. DOI: 10.1038/nature12952.

14. Huang G, Hou C, Shao Y, Wang H, Zhang Q, Li Y, Zhu M. Highly Strong and Elastic GrapheneFibers Prepared from Universal Graphene Oxide Precursors. Scientific reports, 2014, 4:4248. DOI: 10.1038/srep04248.

15. Wang Y, Zhang Q, Jia M, Yang D, Wang J, Li M, Zhang J, Sun Q, Jia Y. Porous graphene for high capacity lithium ion battery anode material. Applied Surface Science, 2016, 363:318-322.

16. www.akkolab.ru.

17. https:/ / graphene-supermarket.com.

18. Ma J, He Y, Zhang W, Wang J, Yang X, Liao X, Ma Z. Rapid communication: An experimental insight into the advantages of in- situ solvothermal route to construct 3D graphene-based anode materials for lithiumion batteries. Nano Energy, 2015, 16:235-246.

19. Cao H, ZhouX, Zheng C, Liu Z. Metal etching method for preparing porous graphene as high performance anode material for lithiumion batteries. Carbon, 2015, 89:41-46.

20. Guo R, Zhao L, Yue W. Assembly of coreshell structured porous carbon-graphene composites as anode materials for lithiumion batteries. Electrochimica Acta, 2015, 152:338-344.

21. Liu X, Wu Y, Yang Z, Pan F, Zhong X, Wang J, Gu L, Yu Y. Nitrogen-doped 3D macroporousgraphene frameworks as anode for high performance lithium-ion batteries. Journal of Power Sources, 2015, 293:799-805.

22. Dao T, Dung H, Jung-Eui R, Kwang-Sun J, Han M. Super-tough functionalized graphene paper as a high-capacity anode for lithium 
ion batteries. Chemical Engineering Journal, 2014, 250:257-266.

23. Oh K, Min C, Sung-Woo K, Gyeong-Ok R, Kwang-Sun J, Han M. Novel graphene papers with sporadic alkyl brushes on the basal plane as a high-capacity flexible anode for lithium ion batteries. Electrocbimica Acta, 2014, 135:478-486.

24. Ahn W, Song H, Park S, Kim K, Shin K, Lim S, Yeon S. Morphology-controlled graphemenanosheets as anode material for lithium-ion batteries. Electrocbimica Acta, 2014, 132:172-179.

25. Li H, Niu R, Liang S, Ma Y, Luo M, Li J, He L. Sulfonated Reduced Graphene Oxide: A High Performance Anode Material for Lithium Ion Battery. ACS Nano, 2015, 10(4):1-7.

26. Zhang J, Guo B, Yang Y, Shen W, Wang Y, Zhou X, Wu H, Guo S. Large scale production of nanoporousgraphene sheets and their application in lithium ion battery. Carbon, 2015, 84:469-478.

27. Hu Y, Li X, Geng D, Cai M, Li R, Sun $\mathrm{X}$. Influence of paper thickness on the electrochemical performances of graphene papers as an anode for lithium ion batteries. Electrochimica Acta, 2013, 91:227-233.

28. Cai D, Wang S, Lian P, Zhu X, Li D, Yang W, Wang H. Superhigh capacity and rate capability of high-level nitrogen-doped graphene sheets as anode materials for lithium-ion batteries. Electrocbimica Acta, 2013, 90:492-497.

29. Ye JC, Charnvanichborikarn S, Worsley MA, Kucheyev SO, Wood BC, Wang YM. Enhanced electrochemical performance of ion-beam-treated 3D graphene aerogels for lithium ion batteries. Carbon, 2015, 85:269-278.

30. Hu Y, He D, Wang Y, Fu M, An X, Zhao $X$. Defect-introduced graphene sheets with hole structure as lithium-ion battery anode. Materials Letters, 2016, 164:278-281.
31. Fu C, Li S, Wang Q. High reversible capacity of Nitrogen-doped graphene as an anode material for lithium-ion batteries. Advanced Materials Research, 2014, 1070-1072:459-464.

32. Jiao L, Wu T, Li H, Lia F, Niu L. High quality graphitized graphene as an anode material for lithium ion batteries. Chem. Commun., 2015, 51:15979-15981.

33. Hassoun J, Bonaccorso F, Agostini M, Angelucci M, Betti M, Cingolani R, Gemmi M, Mariani C, Panero S, Pellegrini V, Scrosati B. An Advanced Lithium-Ion Battery Based on a Graphene Anode and a Lithium Iron Phosphate Cathode. Nano Lett., 2014, 14:4901-4906.

34. Kim H, Park K, Hong J, Kang K. Allgraphene-battery: bridging the gap between supercapacitors and lithium ion batteries. Scientific Reports, 2014, 4:5278. DOI: 10.1038/ srep05278.

35. Vargas O, Caballero A, Morales J, Elia G, Scrosatiw B, Hassoun J. Electrochemical performance of a graphemenanosheets anode in a high voltage lithium-ion cell. Phys. Chem. Chem. Phys., 2013, 15:20444-20446.

36. Jeong $S$, Yang $S$, Jeong $S$, Kim I, Jeong $H$, Han J, Baeg K, Lee G. Monolithic Graphene Trees as Anode Material for Lithium Ion Batteries with High C-Rates. Small, 2015, 11(23):2774-2781.

37. Xu Y, Lin Z, Zhong X, Papandrea B, Huang Y, Duan X. Solvated Graphene Frameworks as High-Performance Anodes for LithiumIon Batteries.Angew. Chem. Int. Ed., 2015, 54:5345-5350.

38. Zhao D, Wang L, Yu P, Zhao L, Tian C, Zhou W, Zhang L, Fu H. From graphite to porous graphene-like nanosheets for high rate lithium-ion batteries.Nano Research., 2015, 8(9):2998-3010.

39. Kim H, Huang X, Guo X, Wen Z, Cui S, Chen J. Novel Hybrid Carbon Nanofiber/ Highly Branched GrapheneNanosheet for Anode Materials in Lithium-Ion Batteries. Appl. Mater. Interfaces, 2014, 6:18590-18596. 
40. Yu L, XiHai J, Jing S. Advances of graphene application in electrode materials for lithium ion batteries. Sci China Tech Sci., 2015, 58(11):1829-1840.

41. Raccichini R, Varzi A, Passerini S, Scrosati B. The role of graphene for electrochemical energy storage. Nature Materials, 2015, 14:271-279.

42. Wu JS, Rui XH, Long GK, Chen WQ, Yan QY, Zhang QC. Pushing Up Lithium Storage through Nanostructured Polyazaacene Analogues as Anode. Angew. Chem., Int. Ed., 2015, 54:7354.

43. Fan XF, Zheng WT, Kuo JL. Adsorption and Diffusion ofLi on Pristine and Defective Graphene. ACS Appl. Mater. Interfaces, 2012, 4:2432.

44. Zhou LJ, Hou ZF, Wu LM. First-Principles Study ofLithium Adsorption and Diffusion on Graphene with Point Defects. J.Phys. Chem. C, 2012, 116:21780.

45. Mukherjee R, Thomas AV, Datta D, Singh E, Li JW, Eksik O, Shenoy VB, Koratkar N. Defect-Induced Plating ofLithium Metal within Porous Graphene Networks. Nat. Commun., 2014, 5:3710.

46. Yao R, Zhao D, Bai L, Yao N, Xu L. Facile synthesis and electrochemical performances of hollow graphene spheres as anode material for lithium-ion batteries. Nanoscale Research Letters, 2014, 9:368. DOI: 10.1186/1556-276X-9-368.

47. Hu C, Lv L, Xue J, Ye M, Wang L, Qu L. Branched GrapheneNanocapsules for Anode Material of Lithium-Ion Batteries. Chem. Mater., 2015, 27:5253-5260.

48. Wen L, Liu C, Song R, Shi Y, Li F, Cheng H, Luo H. Lithiumstorage characteristics and possible applications of graphene materials. ActaChimicaSinica, 2014. 3:333-344.

49. Atabaki M, Kovacevic R. Graphene Composites as Anode Materials in LithiumIon Batteries. Electronic Materials Letters, 2013, $9(2): 133-153$.
50. Qin J, He C, Zhao N, Wang Z, Shi C, Liu E, Li J. Graphene Networks Anchored with Sn@ Graphene as Lithium Ion Battery Anode. ACS Nano, 2014, 8(2):1728-1738.

51. Wu Q, Wang C, Ren J. Sn and $\mathrm{SnO}_{2}$-graphene composites as anode materials for lithiumion batteries. Ionics, 2013, 19:1875-1882.

52. Zhang Y, Jiang L, Wang C. Facile synthesis of $\mathrm{SnO}_{2}$ nanocrystals anchored onto graphemenanosheets as anode materials for lithium-ion batteries. Phys.Chem.Chem.Phys., 2015, 17:20061-20065.

53. ZhouX,BaoJ,DaiZ, GuoY.TinNanoparticles Impregnated in Nitrogen-Doped Graphene for Lithium-Ion Battery Anodes. J. Phys. Chem. C, 2013, 117:25367-25373.

54. Liu H, Huang J, Xiang C, Liu J, Li X. In situ synthesis of $\mathrm{SnO}_{2}$ nanosheet/graphene composite as anode materials for lithiumion batteries. Mater Sci: Mater Electron., 2013, 24:3640-3645.

55. Guo Q, Qin X. Flower-like $\mathrm{SnO}_{2}$ nanoparticles grown on graphene as anode materials for lithium-ion batteries. Solid State Electrochem., 2014, 18:1031-1039.

56. Dhanabalan A, Li X, Agrawal R, Chen C, Wang C. Fabrication and Characterization of $\mathrm{SnO}_{2} /$ Graphene Composites as High Capacity Anodes for Li-Ion Batteries. Nanomaterials, 2013, 3:606-614.

57. Lin J, Peng Z, Xiang C, Ruan G, Yan Z, Natelson D, Tour J. Graphene Nanoribbon and Nanostructured $\mathrm{SnO}_{2}$ Composite Anodes for Lithium Ion Batteries. ACS Nano, 2013, 7(7):6001-6006.

58. Genorio B, Lu W, Dimiev AM, Zhu Y, Raji A, Novosel B, Alemany LB, Tour JM. In Situ Intercalation Replacement and Selective Functionalization of Graphene Nanoribbon Stacks. ACS Nano, 2012, 6:4231-4240.

59. Zhou M, Li X, Wang B, Zhang Y, Ning J, Xiao Z, Zhang X, Chang Y, Zhi L. HighPerformance Silicon Battery Anodes Enabled by Engineering Graphene Assemblies. Nano Lett., 2015, 15:6222-6228. 
60. Gao X, Li J, Xie Y, Guan D, Yuan C. A Multilayered Silicon-Reduced Graphene Oxide Electrode for High Performance Lithium-Ion Batteries. Appl. Mater. Interfaces, 2015, 7:7855-7862.

61. Wang B, Li X, Zhang X, Luo B, Jin M, Liang M, Dayeh S, Picraux S, Zhi L. Adaptable Silicon-Carbon Nanocables Sandwiched between Reduced Graphene Oxide Sheets as Lithium-Ion Battery Anodes. ACS Nano, 2013, 7(2):1437-1445.

62. Chang J, Huang X, Zhou G, Cui S, Hallac P, Jiang J, Hurley P, Chen J. Multilayered Si Nanoparticle/Reduced Graphene Oxide Hybrid as a High-Performance Lithium-Ion Battery Anode. Adv. Mater., 2014, 26:758-764.

63. Hassan F, Rahman Elsayed A, Chabot V, Batmaz R, Xiao X, Chen Z. Subeutectic Growth of Single-Crystal Silicon Nanowires Grown on and Wrapped with Graphene Nanosheets: High-Performance Anode Material for Lithium-Ion Battery. Appl. Mater. Interfaces, 2014, 6:13757-13764.

64. Liu X, Zhang J, Si W, Xi L, Eichler B, Yan C, Schmidt O. Sandwich Nanoarchitectureof Si/Reduced Graphene Oxide Bilayer Nanomembranes for Li-Ion Batteries with Long Cycle Life. ACS Nano, 2015, 9(2):1198-1205.

65. Ko M, Chae S, Jeong S, Oh P, Cho J. Elastic $\alpha$-Silicon Nanoparticle Backboned Graphene Hybridas a Self-Compacting Anode for High-Rate Lithium Ion Batteries. ACS Nano, 2014, 8(8):8591-8599.

66. Li D, Shi D, Liu Z, Liu H, Guo Z. $\mathrm{TiO}_{2}$ nanoparticles on nitrogen-doped graphene as anodematerial for lithium ion batteries. $J$ Nanopart Res., 2013, 15:1674.

67. Liu H, Cao K, Xu X, Jiao L, Wang Y, Yuan H. Ultrasmall $\mathrm{TiO}_{2}$ Nanoparticles in Situ Growth on Graphene Hybrid as Superior Anode Material for Sodium/Lithium Ion Batteries. Appl. Mater. Interfaces, 2015, 7:11239-11245.
68. Zhen M, Zhu X, Zhang X, Zhou Z, Liu L. Reduced Graphene Oxide-Supported $\mathrm{TiO}_{2}$ Fiber Bundles with Mesostructures as Anode Materials for Lithium-Ion Batteries. Chem. Eur. J., 2015, 21:14454-14459.

69. Li W, Wang F, Liu Y, Wang J, Yang J, Zhang L, Elzatahry A, Al-Yongyao D, Zhao D. General Strategy to Synthesize Uniform Mesoporous $\mathrm{TiO}_{2} /$ Graphene/Mesoporous $\mathrm{TiO}_{2}$ Sandwich-Like Nanosheets for Highly Reversible Lithium Storage. Nano Lett., 2015, 15:2186-2193.

70. Zhang Z, Zhang L, Li W, Yu A, Wu P. Carbon-Coated Mesoporous $\mathrm{TiO}_{2}$ Nanocrystals Grown on Graphenefor Lithium-Ion Batteries. Appl. Mater. Interfaces, 2015, 7:10395-10400.

71. Shuvo M, Rodriguez G, Islam T, Karim H, Ramabadran N, Noveron J, Lin Y. Microwave exfoliated graphene oxide $/ \mathrm{TiO}_{2}$ nanowire hybrid for high performancelithium ion battery. J. Appl. Phys., 2015, 118:125102.

72. Chen S, Qin X. Tin oxide-titaniumoxide/ graphene composited as anode materialsfor lithium-ion batteries. J Solid State Electrochem., 2014, 18:2893-2902.

73. Medina P, Zheng H, Fahlman B, Annamalai P, Swartbooi A, Roux L, Mathe M. $\mathrm{Li}_{4} \mathrm{Ti}_{5} \mathrm{O}_{12} /$ graphene nanoribbons composite as anodes for lithium ion batteries. Springer Plus., 2015, 4:643.

74. Zhang Q, Peng W, Wang Z, Li X, Xiong $\mathrm{X}$, Guo H, Wang Z, Wu F. Synthesis and characterization of $\mathrm{Li}_{4} \mathrm{Ti}_{5} \mathrm{O}_{12} /$ graphene composite as anode material with enhanced electrochemical performance. Ionics, 2013, 19:717-723.

75. Sun Y, Hu X, Luo W, Xia F, Huang Y. Reconstruction of Conformal Nanoscale $\mathrm{MnO}$ on Graphene as a High-Capacity and Long-Life Anode Material for Lithium Ion Batteries. Adv. Funct. Mater., 2013, 23:2436-2444.

76. Wu T, Tu F, Liu S, Zhuang S, Jin G, Pan C. $\mathrm{MnO}$ nanorods on graphene as an anode 
material for highcapacity lithium ion batteries. J Mater Sci., 2014, 49:1861-1867.

77. Park A, Kim J, Kim K, Zhang K, Park J, Park J, Lee J, Yoo P. Si-Mn/Reduced Graphene Oxide Nanocomposite Anodes with Enhanced Capacity and Stability for Lithium-Ion Batteries. Appl. Mater. Interfaces, 2014, 6:1702-1708.

78. Chen S, Qin X. Molybdenum oxide-iron oxide/graphene composite as anodematerials for lithium ion batteries. J. Solid State Electrochem., 2015, 19:1867-1874.

79. Zhao Y, Kuai L, Liu Y, Wang P, Arandiyan H, Cao S, Zhang J, Li F, Wang Q, Geng B, Sun H. Well-Constructed Single-Layer Molybdenum Disulfide Nanorose Cross-Linked by Three Dimensional-Reduced Graphene Oxide Network for Superior Water Splitting and Lithium Storage Property. Scientific Reports, 2015, 5:8722. DOI: 10.1038/srep08722.

80. Choi S, Kang Y. Crumpled GrapheneMolybdenum Oxide Composite Powders: Preparation and Application in Lithium-Ion Batteries. ChemSus Chem., 2014, 7:523-528.

81. Kornilov DYu, Gubin SP. Grafen elektrodaktivny material dlya litiy-ionnykh akkumulyatorov [Graphene is electrode active material for lithium-ion batteries]. Intern. Conference "Physico-chemical problems of renewable energetics", Ioffe Institute, Nov. 16-18, 2015, St Petersburg, Publishing House of the Polytechnic. Univ., 2015, p.123.

82. Kim J, Kim D, Jung H, Choi J. Controlled Lithium Dendrite Growth by a Synergistic Effect of Multilayered Graphene Coating and an Electrolyte Additive. Chem. Mater., 2015, 27:2780-2787. 